\title{
Lack of Association between CLEC5A Gene Single-Nucleotide Polymorphisms and Kawasaki Disease in Taiwanese Children
}

\author{
Ya-Ling Yang, ${ }^{1}$ Wei-Pin Chang, ${ }^{2}$ Yu-Wen Hsu, ${ }^{3}$ Wei-Chiao Chen, ${ }^{3}$ \\ Hong-Ren Yu, ${ }^{4,5}$ Chi-Di Liang, ${ }^{5}$ Yao-Ting Tsai, ${ }^{3}$ Ying-Hsien Huang, ${ }^{5}$ \\ Kuender D. Yang, ${ }^{6}$ Ho-Chang Kuo, ${ }^{4,5}$ and Wei-Chiao Chang ${ }^{3,7}$ \\ ${ }^{1}$ Department of Anesthesiology, Kaohsiung Chang Gung Memorial Hospital and Chang Gung University College of Medicine, \\ Kaohsiung 807, Taiwan \\ ${ }^{2}$ Department of Healthcare Management, Yuanpei University, HsinChu 30015, Taiwan \\ ${ }^{3}$ Department of Medical Genetics, College of Medicine, Kaohsiung Medical University, Kaohsiung 807, Taiwan \\ ${ }^{4}$ Division of Allergy, Immunology and Rheumatology of Pediatrics, Kaohsiung Chang Gung Memorial Hospital \\ and Chang Gung University College of Medicine, Kaohsiung 807, Taiwan \\ ${ }^{5}$ Department of Pediatrics, Kaohsiung Chang Gung Memorial Hospital and Chang Gung University College of Medicine, \\ Kaohsiung 807, Taiwan \\ ${ }^{6}$ Department of Medical Research, Show Chwan Memorial Hospital in Chang Bing, Changhua 505, Taiwan \\ ${ }^{7}$ Cancer Center, Kaohsiung Medical University Hospital, Kaohsiung 807, Taiwan
}

Correspondence should be addressed to Ho-Chang Kuo, erickuo48@yahoo.com.tw and Wei-Chiao Chang, wcc@kmu.edu.tw

Received 28 August 2011; Accepted 13 November 2011

Academic Editor: Misao Matsushita

Copyright ( 2012 Ya-Ling Yang et al. This is an open access article distributed under the Creative Commons Attribution License, which permits unrestricted use, distribution, and reproduction in any medium, provided the original work is properly cited.

\begin{abstract}
Background. Kawasaki disease is characterized by systemic vasculitis of unknown etiology. Previous genetic studies have identified certain candidate genes associated with susceptibility to $\mathrm{KD}$ and coronary artery lesions. Host innate immune response factors are involved in modulating the disease outcome. The aim of this study was to investigate CLEC5A (C-type lectin domain family 5) genetic polymorphisms with regards to the susceptibility and outcome of KD. Methods. A total of 1045 subjects (381 KD patients and 664 controls) were enrolled to identify 4 tagging single-nucleotide polymorphisms (tSNPs) of CLEC5A (rs1285968, rs11770855, rs1285935, rs1285933) by using the TaqMan Allelic Discrimination Assay. The Hardy-Weinberg equilibrium was assessed in cases and controls, and genetic effects were evaluated by the chi-square test. Results. No significant associations were noted between the genotypes and allele frequency of the 4 CLEC5A tSNPs between controls and patients. In the patients, polymorphisms of CLEC5A showed no significant association with coronary artery lesion formation and intravenous immunoglobulin treatment response. Conclusions. This study showed for the first time that polymorphisms of CLEC5A are not associated with susceptibility to $\mathrm{KD}$, coronary artery lesion formation, and intravenous immunoglobulin treatment response in a Taiwanese population.
\end{abstract}

\section{Introduction}

Kawasaki disease (KD) is characterized by acute, febrile, and systemic vasculitis and was first described by Kawasaki et al. in 1974 [1]. In developed countries, KD is the leading cause of acquired heart diseases in children [2,3]. KD occurs worldwide and particularly in Japan, Korea, and Taiwan and mainly affects children less than 5 years of age [46]. The most serious complication of $\mathrm{KD}$ is the occurrence of coronary artery lesions (CALs) [7, 8]. The prevalence of KD in children younger than 5 years is the highest in Japan, followed by Korea and Taiwan, and lowest in Europe. Previous studies have either failed to identify causative pathogens for KD or reported discrepant results [9-11]. Therefore, it is possible that a genetic background plays an important role in the pathogenesis of $\mathrm{KD}$.

CLEC5A (C-type lectin domain family 5, member A; also known as myeloid DAP12-associating lectin (MDL-1)) 
contains a C-type lectin-like fold similar to the naturalkiller T-cell C-type lectin domains and is associated with a $12-\mathrm{kDa}$ DNAX-activating protein (DAP12) on myeloid cells [12-14]. Signaling via this complex constitutes a significant activation pathway in myeloid cells and plays an important role in immune defense. Recently, it has been demonstrated that CLEC5A acts as a signaling receptor for proinflammatory cytokine release, and that blockade of CLEC5A-mediated signaling attenuates the production of proinflammatory cytokines by macrophages infected with dengue virus [14]. In contrast, it has been demonstrated that MDL-1 stimulation induces a significant amount of RANTES and macrophage-derived chemokine (MDC) production in cooperation with signaling through TLR in mouse myeloid cells [15]. Furthermore, there is ample evidence that activation of peripheral blood monocytes/macrophages [16-18], proinflammatory cytokines [16], and the RANTES gene play a central role during acute $\operatorname{KD}[19,20]$. A persistent or increased expression of chemokine genes in the convalescent phase in patients is associated with coronary artery lesions $[17,19]$. In addition, infiltration by the cells is notable in affected tissues in autopsy cases and in skin biopsy specimens from KD patients [21].

However, no CLEC5A genetic association with KD has previously been reported. To gain further understanding of the genetic role of CLEC5A in the pathogenesis of $\mathrm{KD}$, the aim of our study was to determine if any CLEC5A SNPs are associated with susceptibility to KD, CAL formation, or IVIG treatment response in Taiwanese children.

\section{Patients and Methods}

2.1. Patients Studied. All study cases were children enrolled from Chang Gung Memorial Hospital, Kaohsiung Medical Center, between 2001 and 2009, who fulfilled the diagnostic criteria for KD. All patients were treated with IVIG $(2 \mathrm{~g} / \mathrm{kg})$ and aspirin as per our previous studies $[7,8,18]$. This study was approved by the Institutional Review Board of Chang Gung Memorial Hospital. Blood samples were collected after informed consent was obtained from parents or guardians. CAL formation was defined as the internal diameter of the coronary artery measuring at least $3 \mathrm{~mm}(4 \mathrm{~mm}$ if the subject was over the age of 5 years) or the internal diameter of a segment at least 1.5 times that of an adjacent segment, as observed in echocardiography $[8,22]$. IVIG responsiveness was defined as defervescence within $48 \mathrm{~h}$ after the completion of IVIG treatment and no recurrence of fever (temperature $>38^{\circ} \mathrm{C}$ ) for at least 7 days after IVIG with marked improvement or normalization of inflammatory signs $[7,8]$.

2.2. DNA Extraction. Blood cells were subjected to DNA extraction by treating them first with $0.5 \%$ SDS lysis buffer and then protease $\mathrm{K}(1 \mathrm{mg} / \mathrm{mL})$ for digestion of nuclear protein for $4 \mathrm{~h}$ at $60^{\circ} \mathrm{C}$. Total DNA was harvested by using a Gentra extraction kit followed by $70 \%$ alcohol precipitation as described in our previous report [23].
TABLE 1: Basal characteristics of the patients with Kawasaki disease and normal controls.

\begin{tabular}{lcc}
\hline Characteristic & Patients with KD & Normal controls \\
\hline & $N=381$ & $N=664$ \\
$\begin{array}{l}\text { Male gender, no. (\%) } \\
\begin{array}{l}\text { Mean (SD) age } \\
\text { (years) }\end{array}\end{array}$ & $\begin{array}{l}\text { 247 }(64.8 \%) \\
\text { Age range (years) }\end{array}$ & $314(55.2 \%)$ \\
$\begin{array}{l}\text { CAL formation, no. } \\
\begin{array}{l}\%) \\
\text { IVIG resistance, no. } \\
(\%)\end{array}\end{array}$ & $37(9.7 \%)$ & $0-7 \pm 4.9$ \\
\hline
\end{tabular}

CAL: coronary artery lesion; IVIG: intravenous immunoglobulin; SD: standard deviation.

2.3. SNPs Selection for CLEC5A. We selected tagging SNPs (tSNPs) of CLEC5A from the release 2.0 Phase II data of the HapMap Project (http://www.hapmap.org). tSNPs were chosen according to the following criteria: $r^{2} \geq 0.8$, the minor allele frequency (MAF) $\geq 10 \%$ in the Han Chinese population, and tSNPs located in exon or $1 \mathrm{~kb}$ UTR.

2.4. Genotyping. Genotyping was carried out using the TaqMan Allelic Discrimination Assay (Applied Biosystems, Foster city, Calif, USA) as per our previous report [24]. The polymerase chain reaction (PCR) was performed using a 96well microplate with an ABI9700 Thermal Cycler. After PCR, fluorescence was detected and analyzed using System SDS software version 1.2.3.

2.5. Statistical Analysis. JMP 8.0 for Windows was used for analysis. Statistical differences between cases and controls in genotype and allele frequency were assessed using the $\chi^{2}$ test or Fisher's exact test. The Hardy-Weinberg equilibrium was assessed using the $\chi^{2}$ test with 1 degree of freedom. Statistical differences in genotype and allele frequency of KD patients with or without CAL formation and patients with IVIG resistance/responsiveness were assessed using the $\chi^{2}$ test. The Bonferroni test was used to correct for multiple tests. Linkage disequilibrium (LD) was assessed for any pair of SNPs, and haplotype blocks were defined using the default setting of the Haploview software 4.1 (Broad Institute, Cambridge, Mass, USA).

\section{Results}

3.1. Lack of Association between CLEC5A tSNPs and the Susceptibility of KD. A total of $381 \mathrm{KD}$ patients and 664 controls were included in this study (Table 1). The distribution of CLEC5A genotypes was in accordance with the HardyWeinberg equilibrium for both cases and controls (Table 2). However, none of the tSNPs was significantly associated with the genotype or allele frequency of the controls or $\mathrm{KD}$ patients under 3 genetic models (dominant, recessive, or allelic models) (Table 2). 
TABLE 2: Genotype and allele frequencies of the CLEC5A gene in controls and patients with Kawasaki disease.

\begin{tabular}{|c|c|c|c|c|c|c|c|c|c|c|}
\hline & Genotype & $\begin{array}{l}\text { Case }(\%) \\
(n=381)\end{array}$ & $\begin{array}{c}\text { Control } \\
(\%) \\
(n=664) \\
\end{array}$ & Allele & $\begin{array}{l}\text { Case }(\%) \\
(n=381)\end{array}$ & $\begin{array}{c}\text { Control (\%) } \\
(n=664)\end{array}$ & $\begin{array}{l}\text { Genotype } P \\
\text { value }\end{array}$ & $\begin{array}{c}\text { Dominant } \\
P \text { value }\end{array}$ & $\begin{array}{c}\text { Recessive } P \\
\text { value }\end{array}$ & $\begin{array}{c}\text { Allelic } P \\
\text { value }\end{array}$ \\
\hline \multirow{3}{*}{ rs1285968 } & GG & $70(18.5)$ & $141(21.5)$ & G & $325(42.9)$ & $596(45.4)$ & \multirow{3}{*}{0.484} & \multirow{3}{*}{0.488} & \multirow{3}{*}{0.245} & \multirow{3}{*}{0.261} \\
\hline & AG & $185(48.8)$ & $314(47.9)$ & A & $433(57.1)$ & $716(54.6)$ & & & & \\
\hline & $\mathrm{AA}$ & $124(32.7)$ & $201(30.6)$ & & & & & & & \\
\hline \multirow{3}{*}{ rs11770855 } & GG & $88(23.5)$ & $147(22.5)$ & G & $366(48.9)$ & $623(47.8)$ & \multirow{3}{*}{0.877} & \multirow{3}{*}{0.643} & \multirow{3}{*}{0.718} & \multirow{3}{*}{0.615} \\
\hline & AG & $190(50.8)$ & $329(50.5)$ & A & $382(51.1)$ & $681(52.2)$ & & & & \\
\hline & AA & $96(25.7)$ & $176(27.0)$ & & & & & & & \\
\hline \multirow{3}{*}{ rs1285935 } & $\mathrm{AA}$ & $29(7.6)$ & $51(7.8)$ & A & $208(27.4)$ & $341(26.1)$ & \multirow{3}{*}{0.640} & \multirow{3}{*}{0.390} & \multirow{3}{*}{0.923} & \multirow{3}{*}{0.519} \\
\hline & GA & $150(39.5)$ & $239(36.5)$ & G & $552(72.6)$ & 967 (73.9) & & & & \\
\hline & GG & $201(52.9)$ & $364(55.7)$ & & & & & & & \\
\hline \multirow{3}{*}{ rs1285933 } & TT & $9(2.4)$ & $30(4.6)$ & $\mathrm{T}$ & $136(18.0)$ & $263(20.2)$ & \multirow{3}{*}{0.194} & \multirow{3}{*}{0.488} & \multirow{3}{*}{0.072} & \multirow{3}{*}{0.228} \\
\hline & СТ & $118(31.2)$ & $203(31.1)$ & $\mathrm{C}$ & $620(82.0)$ & $1041(79.8)$ & & & & \\
\hline & $\mathrm{CC}$ & $251(66.4)$ & $419(64.3)$ & & & & & & & \\
\hline
\end{tabular}

TABLE 3: Genotype and allele frequencies of the CLEC5A gene in patients with Kawasaki disease with or without coronary artery lesion formation (CAL).

\begin{tabular}{|c|c|c|c|c|c|c|c|c|c|c|}
\hline & Genotype & $\begin{array}{l}\text { CAL (\%) } \\
(n=37)\end{array}$ & $\begin{array}{c}\text { Without } \\
(\%) \\
(n=336)\end{array}$ & Allele & $\begin{array}{l}\text { CAL }(\%) \\
(n=37)\end{array}$ & $\begin{array}{c}\text { Without } \\
(\%) \\
(n=336)\end{array}$ & $\begin{array}{c}\text { Genotype } P \\
\text { value }\end{array}$ & $\begin{array}{c}\text { Dominant } \\
P \text { value }\end{array}$ & $\begin{array}{l}\text { Recessive } P \\
\text { value }\end{array}$ & $\begin{array}{l}\text { Allelic } P \\
\text { value }\end{array}$ \\
\hline \multirow{3}{*}{ rs1285968 } & GG & $6(17.1)$ & $62(18.5)$ & G & $31(44.3)$ & $286(42.6)$ & \multirow{3}{*}{0.784} & \multirow{3}{*}{0.568} & \multirow{3}{*}{0.849} & \multirow{3}{*}{0.781} \\
\hline & AG & $19(54.3)$ & $162(48.2)$ & A & $39(55.7)$ & $386(57.4)$ & & & & \\
\hline & $\mathrm{AA}$ & $10(28.6)$ & $112(33.3)$ & & & & & & & \\
\hline \multirow{3}{*}{ rs11770855 } & GG & $8(22.2)$ & $78(23.6)$ & G & 35 (48.6) & $323(48.9)$ & \multirow{3}{*}{0.968} & \multirow{3}{*}{0.921} & \multirow{3}{*}{0.849} & \multirow{3}{*}{0.958} \\
\hline & AG & $19(52.8)$ & $167(50.6)$ & A & $37(51.4)$ & $337(51.1)$ & & & & \\
\hline & AA & $9(25.0)$ & $85(25.8)$ & & & & & & & \\
\hline \multirow{3}{*}{ rs1285935 } & $\mathrm{AA}$ & $3(8.1)$ & $26(7.8)$ & A & $21(28.4)$ & $184(27.5)$ & \multirow{3}{*}{0.985} & \multirow{3}{*}{0.864} & \multirow{3}{*}{0.941} & \multirow{3}{*}{0.867} \\
\hline & GA & $15(40.5)$ & $132(39.4)$ & G & $53(71.6)$ & $486(72.5)$ & & & & \\
\hline & GG & $19(51.4)$ & $177(52.8)$ & & & & & & & \\
\hline \multirow{3}{*}{ rs1285933 } & TT & $1(2.7)$ & $7(2.1)$ & $\mathrm{T}$ & $12(16.2)$ & $119(17.9)$ & \multirow{3}{*}{0.840} & \multirow{3}{*}{0.633} & \multirow{3}{*}{0.812} & \multirow{3}{*}{0.724} \\
\hline & CT & $10(27.0)$ & $105(31.5)$ & C & $62(83.8)$ & $547(82.1)$ & & & & \\
\hline & $\mathrm{CC}$ & $26(70.3)$ & $221(66.4)$ & & & & & & & \\
\hline
\end{tabular}

3.2. Lack of Association between CLEC5A tSNPs and CAL Formation, IVIG Treatment or Aneurysm Formation in KD Patients. In this study, 37 patients (9.9\%) had CAL formation and 49 patients (13.1\%) had resistance to the initial IVIG treatment (Table 1). However, no tSNPs were significantly associated with genotype or allele frequency in the KD patients with or without CAL formation (Table 3). Additionally, the CLEC5A polymorphisms tested in this study failed to show any significant associations with genotype or allele frequency in the KD patients who showed a response to IVIG treatment (Table 4).

3.3. Haplotype Analysis of CLEC5A Genetic Polymorphisms in the Susceptibility, CAL Formation, and IVIG Treatment of KD Patients. We also calculated pairwise linkage disequilibrium (LD) of the SNPs (see Supplemental Figure 1 in supplementary material available online at doi:10.1155/2012/398628) and analyzed the relationship between the haplotypes of
CLEC5A and susceptibility to KD (Supplemental Table 1), CAL formation (Supplemental Table 2) and IVIG treatment response (Supplemental Table 3) in the KD patients. However, none was significantly associated with the phenotype.

\section{Discussion}

The C-type lectin-like super domain (CTLD) family has diverse functions, and in particular, is important in innate immunity including nature killer (NK) function or pathogen recognition [25]. CLEC5A belongs to the Group V "NK cell receptors" family, and MDL-1 expression is upregulated in activated myeloid cells [26] and acts as a signaling receptor for proinflammatory cytokine and chemokine release [14]. Even though a number of reports have demonstrated that KD involves activation of a wide array of immunological elements such as $\mathrm{T}$ cells and macrophages [16-18, 27], with the subsequent release of several cytokines [28], only a few 
TABLE 4: Genotype and allele frequencies of the CLEC5A gene in patients with Kawasaki disease responding or not responding to intravenous immunoglobulin (IVIG) treatment.

\begin{tabular}{|c|c|c|c|c|c|c|c|c|c|c|}
\hline & Genotype & $\begin{array}{c}\text { Resistant } \\
(\%) \\
(n=49)\end{array}$ & $\begin{array}{c}\text { Responsive } \\
(\%) \\
(n=326)\end{array}$ & Allele & $\begin{array}{c}\text { Resistant } \\
(\%) \\
(n=49)\end{array}$ & $\begin{array}{c}\text { Responsive } \\
(\%) \\
(n=326)\end{array}$ & $\begin{array}{c}\text { Genotype } P \\
\text { value }\end{array}$ & $\begin{array}{c}\text { Dominant } \\
P \text { value }\end{array}$ & $\begin{array}{l}\text { Recessive } P \\
\text { value }\end{array}$ & $\begin{array}{c}\text { Allelic } P \\
\text { value }\end{array}$ \\
\hline \multirow{3}{*}{ rs1285968 } & GG & $7(14.6)$ & $63(19.4)$ & G & $37(38.5)$ & $286(44.0)$ & \multirow{3}{*}{0.602} & \multirow{3}{*}{0.397} & \multirow{3}{*}{0.427} & \multirow{3}{*}{0.314} \\
\hline & $\mathrm{AG}$ & $23(47.9)$ & $160(49.2)$ & A & $59(61.5)$ & $364(56.0)$ & & & & \\
\hline & AA & $18(37.5)$ & $102(31.4)$ & & & & & & & \\
\hline \multirow{3}{*}{ rs11770855 } & GG & $12(24.5)$ & $74(23.1)$ & G & $52(53.1)$ & $308(48.1)$ & \multirow{3}{*}{0.437} & \multirow{3}{*}{0.205} & \multirow{3}{*}{0.833} & \multirow{3}{*}{0.363} \\
\hline & $\mathrm{AG}$ & $28(57.1)$ & $160(50.0)$ & A & $46(46.9)$ & $332(51.9)$ & & & & \\
\hline & $\mathrm{AA}$ & $9(18.4)$ & $86(26.9)$ & & & & & & & \\
\hline \multirow{3}{*}{ rs1285935 } & $\mathrm{AA}$ & $2(4.1)$ & $27(8.3)$ & A & $25(25.5)$ & $181(27.8)$ & \multirow{3}{*}{0.567} & \multirow{3}{*}{0.954} & \multirow{3}{*}{0.303} & \multirow{3}{*}{0.629} \\
\hline & GA & $21(42.9)$ & $127(39.1)$ & G & $73(74.5)$ & $469(72.2)$ & & & & \\
\hline & GG & $26(53.0)$ & $171(52.6)$ & & & & & & & \\
\hline \multirow{3}{*}{ rs1285933 } & $\mathrm{TT}$ & $2(4.1)$ & $7(2.2)$ & $\mathrm{T}$ & $15(15.3)$ & $121(18.7)$ & \multirow{3}{*}{0.267} & \multirow{3}{*}{0.233} & \multirow{3}{*}{0.414} & \multirow{3}{*}{0.421} \\
\hline & CT & $11(22.4)$ & $107(33.0)$ & $\mathrm{C}$ & $83(84.7)$ & $527(81.3)$ & & & & \\
\hline & $\mathrm{CC}$ & $36(73.5)$ & $210(64.8)$ & & & & & & & \\
\hline
\end{tabular}

reports have addressed the role of lectin in the pathogenesis of KD.

Several genetic associations with susceptibility to $\mathrm{KD}$ and CAL formation have been reported, but the results are inconsistent [29-32]. Previous genetic association studies have indicated that the intronic SNP ( rs28493229) of ITPKC, 1,4,5-trisphosphate 3-kinase $\mathrm{C}$, reduces gene expression by altering splicing efficiency, and the $\mathrm{C}$ allele contributes to immune hyperreactivity in KD patients [29]. Recently, it has been demonstrated that rs28493229 is associated with susceptibility to KD and CAL formation $[24,29]$. ITPKC is able to regulate the immune system via calcium-dependent NFAT pathways [29]. Similarly, previous studies have indicated that C-type lectin receptors (CLRs) are critical in the activation of the Syk-mediated NFAT signaling pathway [33]. In addition, CLEC5A has been shown to play a key role in host defense and to be involved in dengue virusmediated disease [14]. This finding suggests CLEC5A may be a potential target protein that involves calcium-dependent immune regulation and contributes to the development of coronary artery lesions. However, we did not find evidence to support a genetic role of CLEC5A in the pathogenesis of KD. Since we picked tagging SNPs from the HapMap database, only the tagging SNPs with a minor allele frequency of more than $10 \%$ were selected. Although our tSNP could capture majority of the underlying genetic variances with MAF $>10 \%$ across the CLEC5A gene, the rare causal genetic polymorphisms in CLEC5A may not have been detected in this study. Therefore, we cannot rule out or exclude rare causal genetic polymorphisms in CLEC5A. In addition, there are, at least, seventeen groups of CLRs in vertebrates. Indeed, it has been reported that mannose-binding lectin gene polymorphisms are associated with susceptibility to KD [34] and CAL formation [35]. Thus, large-scale DNA sequencing to CLR family is needed to better understand KD.

In conclusion, this study showed for the first time that tSNPs of CLEC5A are not associated with susceptibility to
$\mathrm{KD}$, CAL formation, and IVIG treatment response in a Taiwanese population.

\section{Abbreviations \\ KD: $\quad$ Kawasaki disease \\ IVIG: Intravenous immunoglobulin \\ CAL: Coronary artery lesions \\ CLEC5A: C-type lectin domain family 5.}

\section{Author's Contribution}

Y.-L. Yang and W.-P. Chang contributed equally to this paper.

\section{Competing Interests}

The authors declare that no competing interests exist.

\section{Acknowledgments}

This study was partly supported by Grants from the National Science Council, Taiwan, ROC (NSC 99-2314-B182A-032-MY2 and NSC 100-2314-B-182A-048-MY3); a Grant from the Center of Excellence for Environmental Medicine, Kaohsiung Medical University (KMU-EM-99-63); Grants from Chang Gung Memorial Hospital, Taiwan, ROC (CMRPG891241 and CMRP8A0121).

\section{References}

[1] T. Kawasaki, F. Kosaki, S. Okawa, I. Shigematsu, and H. Yanagawa, "A new infantile acute febrile mucocutaneous lymph node syndrome (MLNS) prevailing in Japan," Pediatrics, vol. 54, no. 3, pp. 271-276, 1974.

[2] C. L. Wang, Y. T. Wu, C. A. Liu, H. C. Kuo, and K. D. Yang, "Kawasaki disease: infection, immunity and genetics," Pediatric Infectious Disease Journal, vol. 24, no. 11, pp. 998-1004, 2005. 
[3] J. C. Burns and M. P. Glodé, "Kawasaki syndrome," The Lancet, vol. 364, no. 9433, pp. 533-544, 2004.

[4] Y. W. Park, J. W. Han, I. S. Park et al., "Kawasaki disease in Korea, 2003-2005," Pediatric Infectious Disease Journal, vol. 26, no. 9, pp. 821-823, 2007.

[5] W. C. Huang, L. M. Huang, I. S. Chang et al., "Epidemiologic features of Kawasaki disease in Taiwan, 2003-2006," Pediatrics, vol. 123, no. 3, pp. e401-e405, 2009.

[6] Y. Nakamura, M. Yashiro, R. Uehara, I. Oki, K. Kayaba, and H. Yanagawa, "Increasing incidence of Kawasaki disease in Japan: Nationwide survey," Pediatrics International, vol. 50, no. 3, pp. 287-290, 2008.

[7] H. C. Kuo, C. L. Wang, C. D. Liang et al., "Association of lower eosinophil-related T helper 2 (Th2) cytokines with coronary artery lesions in Kawasaki disease," Pediatric Allergy and Immunology, vol. 20, no. 3, pp. 266-272, 2009.

[8] H. C. Kuo, C. D. Liang, C. L. Wang, H. R. Yu, K. P. Hwang, and K. D. Yang, "Serum albumin level predicts initial intravenous immunoglobulin treatment failure in Kawasaki disease," Acta Paediatrica, International Journal of Paediatrics, vol. 99, no. 10, pp. 1578-1583, 2010.

[9] F. Esper, E. D. Shapiro, C. Weibel, D. Ferguson, M. L. Landry, and J. S. Kahn, "Association between a novel human coronavirus and kawasaki disease," Journal of Infectious Diseases, vol. 191, no. 4, pp. 499-502, 2005.

[10] L. Y. Chang, B. L. Chiang, C. L. Kao et al., "Lack of association between infection with a novel human coronavirus ( $\mathrm{HCoV})$, $\mathrm{HCoV}-\mathrm{NH}$, and Kawasaki disease in Taiwan," Journal of Infectious Diseases, vol. 193, no. 2, pp. 283-286, 2006.

[11] T. Ebihara, R. Endo, X. Ma, N. Ishiguro, and H. Kikuta, "Lack of association between New Haven coronavirus and Kawasaki disease," The Journal of Infectious Diseases, vol. 192, no. 2, pp. 351-352, 2005.

[12] A. B. H. Bakker, E. Baker, G. R. Sutherland, J. H. Phillips, and L. L. Lanier, "Myeloid DAP12-associating lectin (MDL)-1 is a cell surface receptor involved in the activation of myeloid cells," Proceedings of the National Academy of Sciences of the United States of America, vol. 96, no. 17, pp. 9792-9796, 1999.

[13] J. Batliner, M. M. Mancarelli, M. Jenal et al., "CLEC5A (MDL1) is a novel PU.1 transcriptional target during myeloid differentiation," Molecular Immunology, vol. 48, no. 4, pp. 714$719,2011$.

[14] S. T. Chen, Y. L. Lin, M. T. Huang et al., "CLEC5A is critical for dengue-virus-induced lethal disease," Nature, vol. 453, no. 7195, pp. 672-676, 2008.

[15] N. Aoki, Y. Kimura, S. Kimura et al., "Expression and functional role of MDL-1 (CLEC5A) in mouse myeloid lineage cells," Journal of Leukocyte Biology, vol. 85, no. 3, pp. 508-517, 2009.

[16] T. Matsubara, T. Ichiyama, and S. Furukawa, "Immunological profile of peripheral blood lymphocytes and monocytes/macrophages in Kawasaki disease," Clinical and Experimental Immunology, vol. 141, no. 3, pp. 381-387, 2005.

[17] Y. F. Cheung, O. Karmin, S. C. F. Tam, and Y. L. Siow, "Induction of MCP1, CCR2, and iNOS expression in THP-1 macrophages by serum of children late after kawasaki disease," Pediatric Research, vol. 58, no. 6, pp. 1306-1310, 2005.

[18] H. C. Kuo, C. L. Wang, C. D. Liang et al., "Persistent monocytosis after intravenous immunoglobulin therapy correlated with the development of coronary artery lesions in patients with Kawasaki disease," Journal of Microbiology, Immunology and Infection, vol. 40, no. 5, pp. 395-400, 2007.

[19] M. Wong, E. D. Silverman, and E. N. Fish, "Evidence for RANTES, monocyte chemotactic protein-1, and macrophage inflammatory protein- $1 \beta$ expression in Kawasaki disease," Journal of Rheumatology, vol. 24, no. 6, pp. 1179-1185, 1997.

[20] H. S. Kim, W. D. Kim, and Y. H. Lee, "Production and expression of Gro- $\alpha$ and RANTES by peripheral blood mononuclear cells Isolated from patients with Kawasaki disease and measles," Journal of Korean Medical Science, vol. 18, no. 3, pp. 381-386, 2003.

[21] M. Terai, Y. Kohno, M. Namba et al., "Class II major histocompatibility antigen expression on coronary arterial endothelium in a patient with Kawasaki disease," Human Pathology, vol. 21, no. 2, pp. 231-234, 1990.

[22] S. T. Shulman, J. De Inocencio, and R. Hirsch, "Kawasaki disease," Pediatric Clinics of North America, vol. 42, no. 5, pp. 1205-1222, 1995.

[23] K. D. Yang, J. C. Chang, H. Chuang et al., "Gene-gene and gene-environment interactions on IgE production in prenatal stage," Allergy, vol. 65, no. 6, pp. 731-739, 2010.

[24] H. C. Kuo, K. D. Yang, S. H. Juo et al., "Itpkc single nucleotide polymorphism associated with the kawasaki disease in a taiwanese population," PLOS ONE, vol. 6, no. 4, Article ID e17370, 2011.

[25] A. Cambi, M. Koopman, and C. G. Figdor, "How C-type lectins detect pathogens," Cellular Microbiology, vol. 7, no. 4, pp. 481-488, 2005.

[26] A. N. Zelensky and J. E. Gready, "The C-type lectin-like domain superfamily," FEBS Journal, vol. 272, no. 24, pp. 61796217, 2005.

[27] K. Ikeda, K. Yamaguchi, T. Tanaka et al., "Unique activation status of peripheral blood mononuclear cells at acute phase of Kawasaki disease," Clinical and Experimental Immunology, vol. 160, no. 2, pp. 246-255, 2010.

[28] S. T. Shulman and A. H. Rowley, "Advances in Kawasaki disease," European Journal of Pediatrics, vol. 163, no. 6, pp. 285-291, 2004.

[29] Y. Onouchi, T. Gunji, J. C. Burns et al., "ITPKC functional polymorphism associated with Kawasaki disease susceptibility and formation of coronary artery aneurysms," Nature Genetics, vol. 40, no. 1, pp. 35-42, 2008.

[30] H. Chi, F. Y. Huang, M. R. Chen et al., "ITPKC gene SNP rs28493229 and Kawasaki disease in Taiwanese children," Human Molecular Genetics, vol. 19, no. 6, Article ID ddp586, pp. 1147-1151, 2010.

[31] M. T. Lin, J. K. Wang, J. I. Yeh et al., "Clinical implication of the C allele of the ITPKC gene SNP rs28493229 in kawasaki disease: association with disease susceptibility and BCG scar reactivation," The Pediatric Infectious Disease Journal, vol. 30, pp. 148-152, 2011.

[32] C. Shimizu, S. Jain, M. L. Hibberd et al., "Transforming growth factor- $\beta$ signaling pathway in patients with Kawasaki disease," Circulation: Cardiovascular Genetics, vol. 4, no. 1, pp. 16-25, 2011.

[33] A. Mócsai, J. Ruland, and V. L. J. Tybulewicz, "The SYK tyrosine kinase: a crucial player in diverse biological functions," Nature Reviews Immunology, vol. 10, no. 6, pp. 387-402, 2010.

[34] S. Sato, H. Kawashima, Y. Kashiwagi, T. Fujioka, K. Takekuma, and A. Hoshika, "Association of mannose-binding lectin gene polymorphisms with Kawasaki disease in the Japanese," International Journal of Rheumatic Diseases, vol. 12, no. 4, pp. 307-310, 2009.

[35] M. H. Biezeveld, I. M. Kuipers, J. Geissler et al., "Association of mannose-binding lectin genotype with cardiovascular abnormalities in Kawasaki disease," The Lancet, vol. 361, no. 9365, pp. 1268-1270, 2003. 

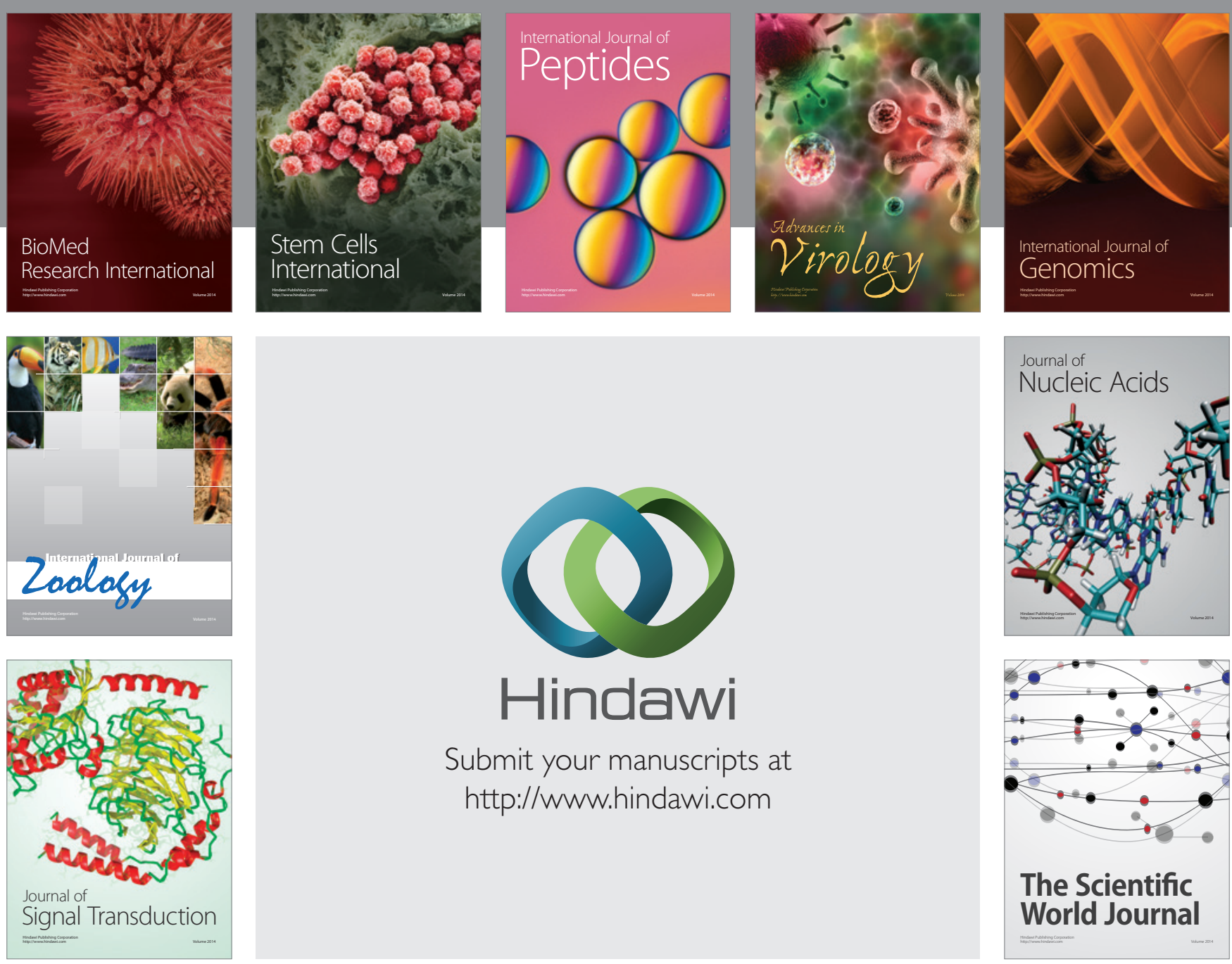

Submit your manuscripts at

http://www.hindawi.com
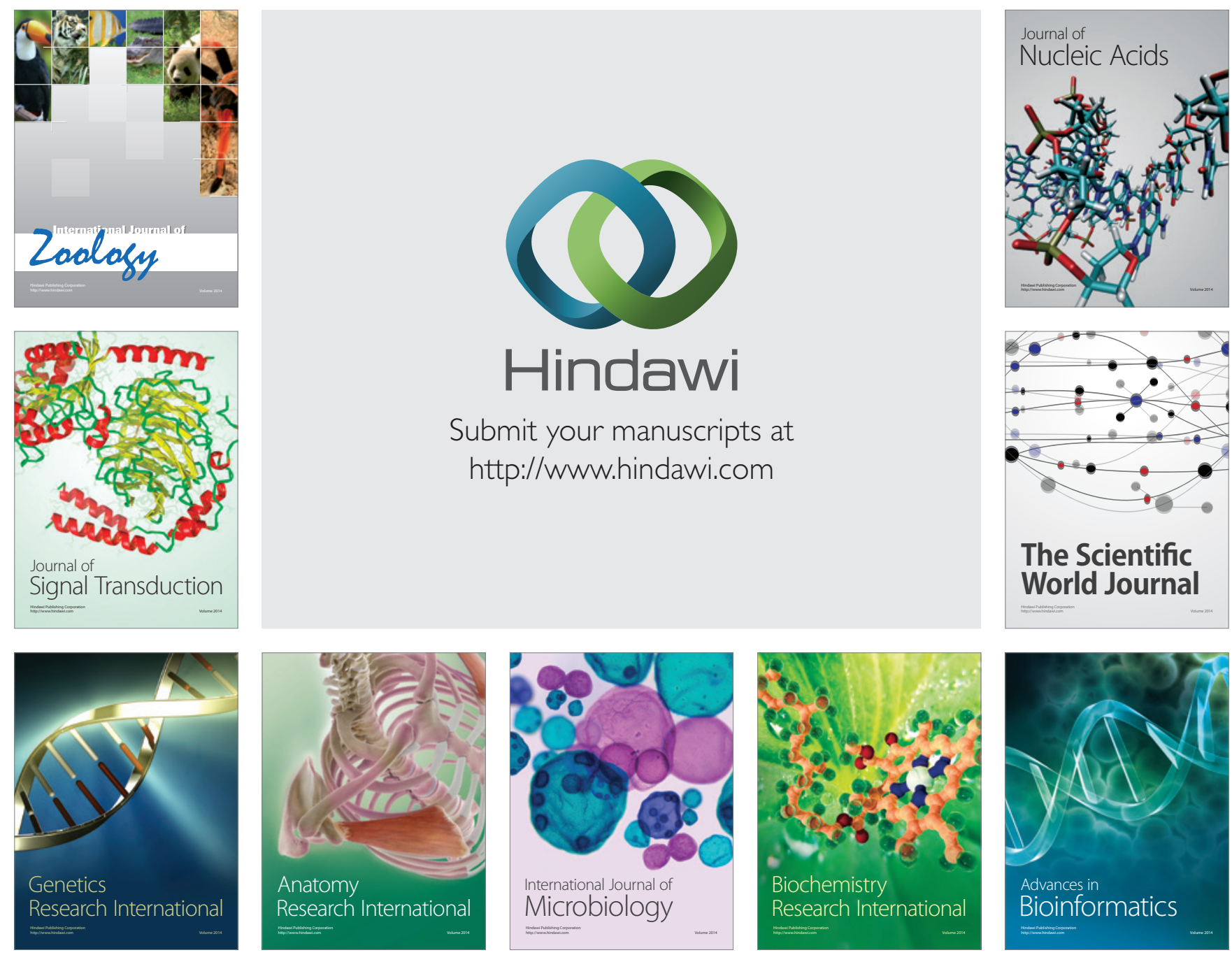

The Scientific World Journal
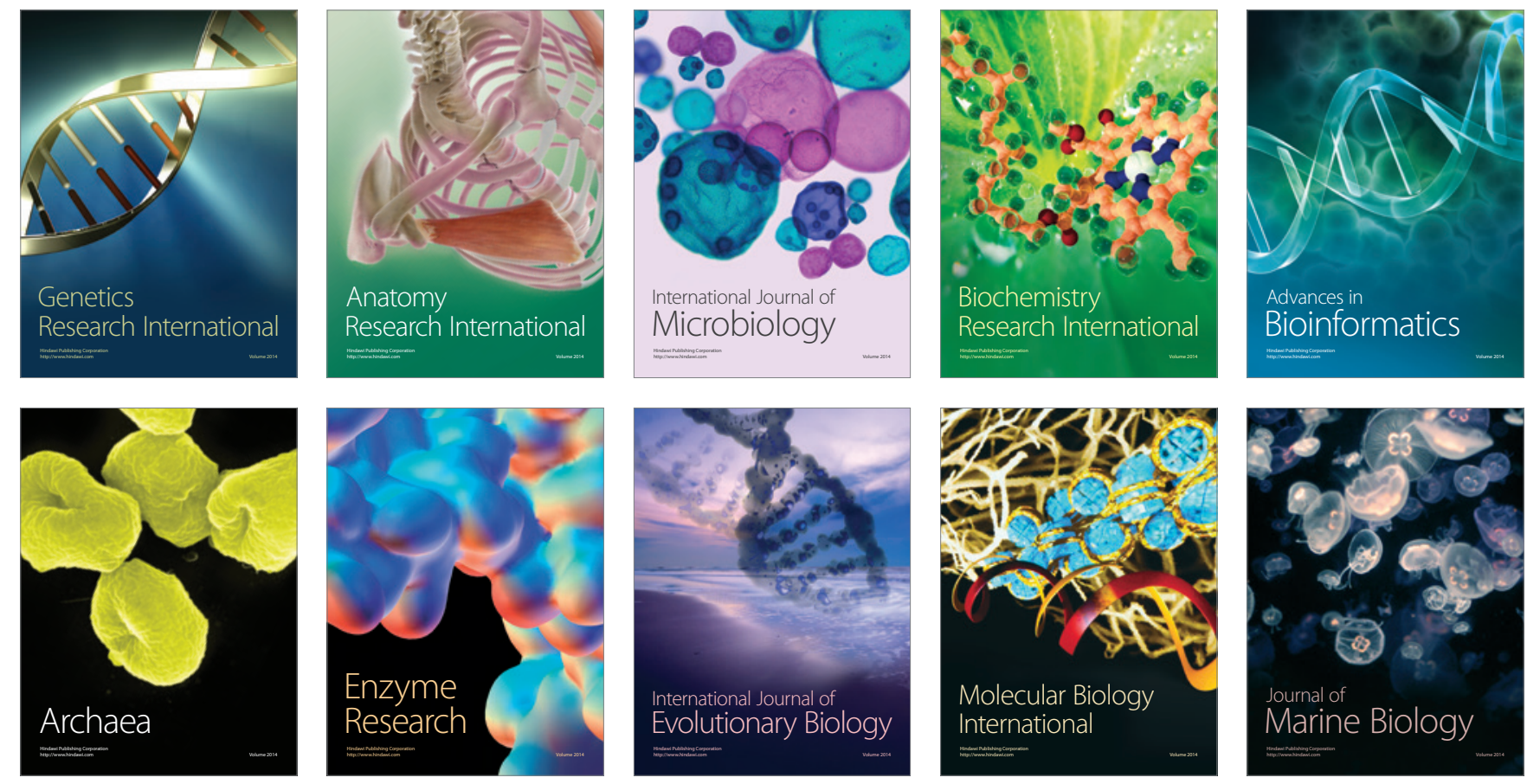